\title{
Através do espelho kantiano: observações sobre Fichte e o idealismo (alemão)
}

Tom Rockmore

\section{(2) OpenEdition \\ Journals}

Edição electrónica

URL: http://journals.openedition.org/ref/410

DOI: $10.4000 /$ ref.410

ISSN: 2258-014X

Editora

EuroPhilosophie Editions

Refêrencia eletrónica

Tom Rockmore, «Através do espelho kantiano: observações sobre Fichte e o idealismo (alemão) », Revista de Estud(i)os sobre Fichte [Online], 6 | 2013, posto online no dia 03 junho 2014, consultado o 08 setembro 2020. URL : http://journals.openedition.org/ref/410 ; DOI : https://doi.org/10.4000/ref.410

Este documento foi criado de forma automática no dia 8 setembro 2020

(c) EuroPhilosophie 


\title{
Através do espelho kantiano: observações sobre Fichte e o idealismo (alemão)
}

\author{
Tom Rockmore
}

1 Através do espelho é a continuação de Alice no país das maravilhas. O espelho permite a Alice atravessá-lo e entrar em um mundo alternativo. $O$ idealismo alemão é um mundo alternativo àquele em que vivemos. Ainda estamos à espera do espelho que vai nos permitir compreender a relação complexa entre Kant e o idealismo alemão póskantiano. Este artigo examina esta relação, ao esboçar uma visão geral do idealismo alemão e, dentro dele, da relação entre Fichte e Kant.

2 A relação entre Fichte e Kant, muitas vezes discutida, permanece obscura e até paradoxal. Fichte reivindica, de modo enfático e implausível, ser um kantiano ultraortodoxo, e até mais kantiano do que Kant, se isto for possível. Ainda assim, ele também é classificado como um idealista alemão, embora Kant seja freqüentemente considerado um não idealista, ou melhor, um crítico do idealismo. Se Kant não é um idealista, e Fichte é, então existe uma tensão, e talvez até simplesmente uma contradição, entre as afirmações que Fichte é um kantiano e um idealista. A visão segundo a qual Kant não é um idealista, mas Fichte é, sugere que, se Fichte é um kantiano, então não é um idealista, ou, ao contrário, que tanto Kant como Fichte são idealistas. Só que, se Kant é um idealista, ainda se precisa mostrar como relacionar o idealismo kantiano com outras formas de idealismo, e como esclarecer a relação entre Kant e Fichte, ou entre Kant e o idealismo alemão que começa com Fichte. De qualquer modo, precisamos entender o que significam "idealismo" e "idealismo alemão", para reivindicar que a versão de Fichte do idealismo alemão é kantiana e, portanto, para legitimar a reivindicação fichtiana a ser um kantiano genuíno, em um sentido mais do que trivial. 


\section{Marxismo, filosofia analítica e "idealismo"}

3 Considerando que uma compreensão do idealismo alemão pressupõe uma compreensão do idealismo, começarei fazendo algumas observações sobre o segundo conceito. Os opositores do idealismo pressupõem freqüentemente que exista alguma aceitação tácita e partilhada que identifique os idealistas. Se o idealismo pressupõe uma aceitação tácita de algum tipo, então parece que não existe um idealismo, pois nunca houve nada parecido com um acordo entre os observadores sobre o que sequer o nome quer dizer. Segue-se que há apenas aqueles que são considerados idealistas, e que não mantêm relações entre si, ou melhor, que se consideram idealistas -o que, paradoxalmente, é diferente de afirmar que exista algo chamado idealismo.

4 Podemos ilustrar este ponto referindo-nos ao marxismo e à filosofia analítica angloamericana, duas das tendências principais a percorrer o século XX. Ambas emergiram de uma refutação do idealismo, o qual definem de modos bem diferentes. Engels, que inventou o marxismo, oferece uma leitura influente, mas tendenciosa, de Marx. De acordo com Engels, a diferença entre o idealismo e o materialismo consiste na dúvida sobre se as idéias precedem as coisas ou vice-versa. Em sua visão, o idealismo desce das idéias para o mundo, enquanto o materialismo se alça do mundo para as idéias. Engels afirma que o idealismo apresenta uma compreensão do mundo social distorcida pela ideologia, que o materialismo supera.

5 A filosofia analítica conta uma história diferente. Junto com Bertrand Russell, G. E. Moore fundou a filosofia analítica na Inglaterra. É bem sabido que Kant apresentou uma "refutação do idealismo" na segunda edição da Crítica da razão pura. Retornarei à visão de Kant abaixo. Num artigo famoso, muito citado, mas raramente lido, Moore empreende, novamente, a "refutação do idealismo". Segundo Moore, todas as variantes do idealismo compartilham a negação da existência do mundo externo. Moore acredita que pode provar que o mundo exterior existe mediante o senso comum. Engels e Moore, marxismo e filosofia analítica, entendem o "idealismo" de modo diverso, mas igualmente problemático. Segundo Engels, a visão distorcida do idealismo só pode ser compreendida e corrigida de um ponto de vista materialista apresentado na análise sistemática do capitalismo moderno de Marx. Esta abordagem é problemática. Um problema é se, como quer Engels, Marx é materialista em algum sentido relevante. Para Moore, ao contrário, os idealistas acreditam em algumas idéias bem bizarras, que podem ser refutadas pela afirmação do senso comum. A dificuldade não está em formular uma análise nova e mais profunda, mas, ao contrário, em retornar ao que os indivíduos, supostamente, sempre souberam no nível do senso comum. Ironicamente, assim como Berkeley, o idealista notório que rejeita a ciência em nome da cristandade, Moore, o anti-idealista, acredita que o remédio para o idealismo está em afirmar verdades do senso comum que são mais profundas que as teorias sobre o mundo.

\section{Algumas formas de idealismo}

Claramente, o marxismo e a filosofia analítica compreendem o "idealismo" de forma diferente. 0 que para o marxismo é uma distorção ideológica é para a filosofia analítica uma negação da crença na existência do mundo exterior por parte do senso comum. A diferença entre estes dois modos de entender o idealismo não chega a ser uma surpresa, 
já que não existe uma visão normativa do termo que seja aceita por aqueles que se supõe serem idealistas ou também que estudam várias formas de idealismo.

7 Para discutir o idealismo, será útil identificar várias maneiras de usar o termo. Uma indicação é dada pela etimologia, que aponta para uma ciência das idéias bem como dos ideais. Há distinções familiares entre o idealismo político, epistêmico e de outros tipos. $\mathrm{O}$ idealismo epistêmico, aquele que surge em contextos epistêmicos, refere-se freqüentemente, ou talvez sempre, à relação entre idéias e objetos cognitivos, ou ao mundo, como quer que o definamos.

8 Para os propósitos presentes, podemos identificar apenas quatro dos sentidos em que idealismo é usado rotineiramente na tradição filosófica. 0 idealismo platônico é um modo de referir-se à famosa teoria das idéias ou das formas. Não conhecemos, nem podemos determinar agora os contornos da sua posição, se é que Platão teve uma. Ainda assim, a crença difundida é que ele sustentou uma teoria das formas ou idéias, que ele descreve de modos diferentes, em diálogos diferentes, e que aparentemente nunca atinge uma forma final. A teoria que emerge do Fédon, e que Sócrates descreve como uma substituta para as teorias causais da ciência natural então contemporâneas, compreende várias etapas nos diálogos tardios, é criticada por Aristóteles na Metafísica, por Platão no Parmênides, e assim por diante.

9 Uma segunda forma de idealismo, que, até onde eu saiba, é raramente ou jamais mencionada, surge na filosofia moderna. A filosofia moderna exibe muitas variantes sobre o tema da relação epistêmica entre as idéias e o mundo. Este tema é comum ao racionalismo (Descartes) e empirismo (Locke). A posição de Locke é descrita às vezes como "new way of ideas" (modo novo das idéias). Se considerarmos que o "modo antigo das idéias" descreve o platonismo, então o modo novo pode ser considerado o que descreve o esforço generalizado e pré-kantiano de entender o conhecimento como a relação das idéias que estão na mente com o mundo.

10 Considera-se o "idealismo alemão", de modo habitual, aplicável a Kant e aos idealistas alemães pós-kantianos que o seguiram, ou, ainda, a estes, mas não ao autor da filosofia crítica. $O$ "idealismo britânico" se refere a uma série de visões díspares formuladas por pensadores britânicos, que freqüentemente se interessaram por vários filósofos alemães, que no entanto nada têm em comum. A sua reunião aparenta estar baseada mais firmemente naquilo que representaram para a filosofia analítica, do modo como esta estava emergindo na Inglaterra na virada do século $\mathrm{XX}$, do que em qualquer pacto doutrinal que tenham feito. Assim, Coleridge se interessou por Schelling, Green por Kant, McTaggart (um ateu) por Hegel, Bradley (um teísta) por Hegel, e assim por diante.

\section{“Idealismo alemão"}

11 Embora o termo "idealismo alemão" seja amplamente difundido, não há acordo sobre o que significa. Hegel, que considera Kant um idealista, inventou a noção de uma tradição idealista alemã, portanto do idealismo alemão, já no seu primeiro texto filosófico. No Differenzschrift ele indica formas de idealismo nos escritos de Kant, Fichte e Schelling. $\mathrm{Na}$ Crítica da razão pura, Kant sugere que sua filosofia é a primeira teoria crítica e que não pode ser modificada. Kant sugere mais tarde que não pode haver mais de uma única teoria verdadeira. Se isto é correto, então outras teorias não podem diferir fundamentalmente da de Kant e reivindicar ser corretas. Seguindo Kant a este respeito, 
Hegel, coerentemente, apresenta Fichte e Schelling, pensadores altamente originais, como tendo sustentado versões da filosofia crítica.

12 Hegel compreende a filosofia genuína como filosofia especulativa. No Differenzschrift ele identifica quatro formas da filosofia especulativa que ele associa aos nomes de Kant, Fichte, Schelling e, por implicação, ao seu. Segundo Hegel, Kant e Fichte foram idealistas subjetivos, incapazes de proceder do sujeito até o objeto independente da mente, até o mundo. Schelling é um idealista objetivo graças ao seu interesse na filosofia da natureza e, embora Hegel não identifique a sua própria posição por um termo específico, a tradição lhe atribui o idealismo absoluto.

13 Esta leitura hegeliana, quádrupla, da tradição idealista alemã sugere que esta se desenvolveu de modo teleológico, como Kroner formulou mais tarde: de Kant a Hegel. Kroner leva adiante a leitura que Lask faz de Fichte, que ele estende a toda a tradição alemã idealista. Nesta abordagem, Kant é a figura inicial e Hegel marca o ponto final. Hegel é a apoteose de uma série de desenvolvimentos começando com Kant. Fichte e Schelling são apenas figuras de transição, importantes por si mesmas mas ainda mais importantes em vista do seu papel mediador entre Kant e Hegel.

14 Este leitura hegeliana do idealismo alemão é útil, mas controversa. Depois da morte de Hegel, ela foi quase imediatamente contestada por Schelling, o antigo colega de quarto de Hegel. Ao enfatizar a diferença entre uma filosofia positiva e uma negativa, Schelling catapulta os seus próprios escritos tardios ao apogeu da tradição idealista alemã. Contudo, esta perspectiva é útil, quando aponta o desenvolvimento mediante uma interação dialética entre Fichte, Schelling e Hegel, todos eles, dir-se-ia, disputando a herança de Kant. Cada um deles se apresenta como seu único sucessor legítimo, como aquele que conduz corretamente a herança do falecido e consuma a revolução copernicana.

15 Qualquer esforço para se apropriar da herança kantiana pressupõe uma compreensão da filosofia crítica. Segundo Kant, é possível diferenciar entre o espírito e a letra de uma teoria. Isto sugere a possibilidade de identificar o espírito da filosofia crítica. Uma vez que os observadores continuam a discordar sobre a posição de Kant, a sua obra pode ser descrita de maneiras diferentes. Assim, Hegel sublinhou as dimensões epistêmicas da filosofia crítica, que ele transforma na sua própria abordagem fenomenológica. Schelling diferencia entre uma filosofia positiva e uma negativa, ao apontar a sua própria posição como o resultado bem-sucedido do idealismo alemão. Heidegger sugere que a obra de Kant é ontológica ao antecipar a sua própria ontologia fenomenológica.

16 Hegel lê Kant como um idealista epistêmico, comprometido com uma abordagem idealista do problema do conhecimento. Uma leitura epistêmica de Kant, e por conseguinte do idealismo alemão, foi contestada de várias maneiras no debate recente. Uma contestação advém da revisão da lista de participantes na tradição idealista alemã. A lista quádrupla de Hegel dos quatro grandes é aumentada por aqueles que indicam Leibniz, Hölderlin, mas também Krause e talvez até Marx como membros desta tradição. Além disso foi sugerido, por exemplo, que o idealismo alemão pode ser lido como um esforço para construir um sistema de refutação do ceticismo, numa das versões enquanto a refutação do chamado ceticismo de Agrippa.

17 Há ainda aqueles que sugerem que Kant não é idealista de forma alguma, ou que não precisamos sequer levar o idealismo em consideração ao interpretar a sua posição. Kant descreve a sua posição como idealismo transcendental e também como realismo 
empírico. Strawson dispensa o primeiro, enfatizando o segundo e levando a uma visão de Kant como um filósofo analítico primevo, alguém que os observadores detectam como interessado no problema da referência semântica. Esta visão não-idealista de Kant foi estendida recentemente até Hegel, que alguns observadores consideram adotar doutrinas analíticas padrão como referência semântica (Bedeutungstheorie), inferência, etc.

\section{Idealismo kantiano e fichtiano e subjetividade}

Para ver como Fichte se refere a Kant, precisamos antes discutir suas visões do idealismo. Eu me concentrarei nas suas concepções respectivas do sujeito, por duas razões. Em primeiro lugar, a ênfase sobre o sujeito é um elemento chave da filosofia moderna, incluindo aí a epistemologia, a ética (concebida de modo amplo), a estética e outras subdisciplinas filosóficas. Na epistemologia, esta ênfase se manifesta numa abordagem amplamente partilhada da objetividade mediante a subjetividade, ou ainda baseada nela. Em segundo lugar, acredito que as diferenças nas visões de Kant e Fichte da subjetividade são cruciais para a distinção entre a filosofia crítica e o idealismo alemão pós-kantiano, inclusive a filosofia transcendental de Fichte.

A subjetividade é um tema persistente e complexo, mas central ao idealismo alemão. Segundo Kant, sua filosofia crítica culmina na sua concepção transcendental do sujeito. É impossível exagerar a importância da revisão que Fichte faz da visão kantiana da subjetividade para o idealismo alemão pós-kantiano.

20 Várias diferenças distanciam o modo kantiano e fichtiano de conceber o sujeito. Uma maneira de formular este tópico é que o conceito kantiano do sujeito deriva de uma adesão prévia a uma concepção normativa de conhecimento, em sentido pleno, como necessariamente a priori. Para Fichte, por outro lado, a concepção de sujeito precede e determina a teoria do conhecimento, ao invés de ser determinada por ela, numa transposição do plano a priori para o plano a posteriori. Ao contrário de Kant, que é um pensador do a priori, a filosofia alemã pós-kantiana é a posteriori. Esta mudança é central para a emergência de um idealismo alemão pós-kantiano, cujos representantes mais proeminentes, a este respeito, todos seguem Fichte.

21 Kant compreende o sujeito em termos de tipos diferentes de atividades requeridas, em princípio, para demonstrar a possibilidade de tipos diferentes de experiência. As últimas incluem o conhecimento, ou razão teórica, moralidade ou razão prática e estética. Hegel critica a concepção fichtiana de estética, embora Fichte diga pouco a respeito da estética, e talvez nada significativo. Sua teoria do sujeito se centra na relação entre a razão prática e a teórica, a qual, como Kant, ele entende mediante formas relativas de atividade.

Kant e Fichte se distinguem em sua compreensão da natureza do sujeito que, para o primeiro, reduz-se a uma função epistemológica na sua análise transcendental, mas para Fichte é um ser humano finito. Kant é um pensador transcendental, de forma resoluta, e comprometido com uma análise transcendental das condições do conhecimento empírico. O sujeito de Kant funciona no âmbito da sua teoria epistemológica como um modo de evitar a redução à psicologia das assim chamadas condições lógico-transcendentais do conhecimento. Um modo de expor este assunto é dizendo que Kant antecipa e busca evitar o que Husserl, mais tarde, chamará 
psicologismo. A teoria fichtiana do sujeito emerge quando se levam até o fim as implicações da concepção kantiana da chamada unidade transcendental da apercepção.

A tese básica de Kant é que o conhecimento requer um sujeito ativo. A teoria kantiana do conhecimento gira em torno da "revolução copernicana", uma expressão que Kant nunca usa para descrever sua posição mas que foi usada para descrevê-la por contemporâneos próximos seus, incluindo Reinhold e Schelling. A revolução copernicana pode ser caracterizada brevemente como uma tese assim chamada construtivista, segundo a qual uma condição do conhecimento necessária mas não suficiente é que o sujeito precisa construir aquilo que conhece. Isto resulta numa oposição básica entre as teorias construtivistas e representacionais da teoria do conhecimento. Segundo a teoria representacional, o conhecimento consiste em encontrar, revelar ou descobrir o objeto cognitivo, que para o construtivismo, ao contrário, é construído, fabricado ou produzido.

$\mathrm{O}$ construtivismo remonta à tradição da primeira geometria grega. É reintroduzido na tradição moderna por Hobbes e Vico, e depois disso, de forma independente, por Kant. A versão kantiana da tese construtivista pode ser parafraseada como uma reivindicação da unidade de sujeito e objeto, subjetividade e objetividade, conhecedor e conhecido. Esta mesma unidade é descrita, mais tarde, como a identidade da teoria da identidade.

A tese kantiana sobre o sujeito afirma a unidade entre sujeito e objeto, portanto concerne à relação entre sujeito e objeto. A posição de Kant, de modo incompleto, sintetiza dois elementos inconsistentes: uma visão do sujeito passivo como afetado por um objeto independente da mente e, além disso, do sujeito como ativo ao construir objetos da percepção, experiência e conhecimento. Kant, com efeito, tem duas teorias diferentes, ou, melhor dizendo, duas partes de uma explicação englobante do conhecimento. Em uma parte, há uma relação causal entre sujeito e objeto, mente e mundo; na outra, o sujeito cognitivo constrói o seu mundo, por assim dizer.

Fichte basicamente repensa -como total e unicamente ativo- o sujeito de Kant, que é tanto passivo quando ativo. Ele transforma a descrição interacionista da relação entre sujeito e um númeno incognoscível em uma interação entre um sujeito ativo e o objeto da experiência. Fichte expõe os contornos básicos desta nova teoria do sujeito em considerações breves no início da GWL (1794/95). Segundo Fichte, o sujeito, ou eu, que é posto, oferece a perspectiva mediante a qual pensar o objeto, ou não-eu, bem como a interação dos dois.

Três pontos devem ser mencionados. Primeiro, a teoria fichtiana do sujeito se desenvolve ao longo de um certo tipo de dialética ou de interação dialética entre sujeito e objeto, sujeito e mundo. Fichte toma o sujeito como o ponto básico a partir do qual construirá sua teoria inteira. Qualquer apelo ao sujeito do conhecimento requer um objeto, ou não-sujeito, entendido por meio do sujeito e da sua interrelação. Esta linha de raciocínio, baseada na concepção de Kant de sujeito transcendental, na verdade a vira do avesso, por assim dizer, no que diz respeito a um ser humano finito. 0 resultado é uma transição de um plano a priori para um a posteriori. Sugere-se freqüentemente que a epistemologia atinge o seu ápice e o seu fim em Kant, já que os pensadores, mais tarde, simplesmente abandonam a sua ênfase no conhecimento objetivo. Esta tese, que não se aplica a nenhum dos idealistas alemães sucessores de Kant, tampouco é verdadeira em relação a Fichte. Fichte não abandona o interesse de Kant pela objetividade. Ou melhor, ele a repensa como dependente da subjetividade, e restrita por ela, no contexto de uma interrelação entre seres humanos finitos e objetos externos, ou 
entre seres humanos finitos e o seu mundo circundante. Na posição de Fichte, o que entendemos por objetividade só pode ser entendido mediante a subjetividade.

\section{Algumas consequências da concepção fichtiana da subjetividade}

28 A transição importante de Fichte, do plano a priori para o plano a posteriori, foi acompanhada de diferentes modo pelos seus sucessores idealistas alemães. Mencionarei apenas três pontos relativos: à natureza do sujeito, ao termo "transcendental" e à relação entre as teorias de Fichte e Kant.

Em primeiro lugar, Fichte resolve o problema kantiano da unidade entre sujeito e objeto. Kant está interessado em uma pergunta que descreve na sua fase madura, na Lógica [editada por] Jäsche, como: o que é o homem? Embora ele pense o sujeito em termos de tipos de atividades, é incapaz de pensar a unidade do sujeito. Este problema, que perpassa todo o seu período crítico, atinge o auge na Crítica da faculdade do juízo. Aqui, ele propõe duas formas de relação entre a razão pura e a prática, ao subordinar a primeira à segunda, e ao relacionar ambas mediante o juízo estético. Ainda assim, Kant é incapaz de apreender a unidade do sujeito implícita na abordagem transcendental, unidade que Fichte apreende ao inverter a relação entre a atividade humana e suas formas. Portanto, Fichte aperfeiçoa a tentativa de Kant de apreender o sujeito, com a transição do a priori para o a posteriori.

Uma segunda diferença diz respeito ao "transcendental". o significado e a importância deste termo familiar são obscuros. A reivindicação de Kant a ter dissolvido ou resolvido as questões principais da filosofia mediante a filosofia crítica é contraditada pelo desenvolvimento pós-kantiano do debate. o debate pós-kantiano inclui teorias kantianas e não-kantianas. Uma vez que Kant subjuga o sucesso da sua posição ao seu estatuto transcendental, é, paradoxalmente, obscuro se Kant é um filósofo transcendental em um sentido mais do que normativo. $O$ sentido em que se pode dizer $o$ mesmo de Fichte também é obscuro. Schelling e Hegel aceitam a tese de Fichte de que a Wissenschaftslehre deste seja filosofia transcendental (Transzendentalphilosophie). Contudo, se o sujeito fichtiano não é um simples postulado epistemológico, mas ao contrário um ser humano finito, e se a teoria é a posteriori e não a priori, então "transcendental" significa coisas diferentes para Kant e Fichte.

31 Uma terceira diferença diz respeito à teoria do conhecimento fichtiana. A dificuldade consiste em entender como a posição de Fichte pode pretender ter realizado de modo razoável as intenções de Kant, a despeito da sugestão que ele seja mais kantiano até do que o próprio Kant, embora divirja claramente sobre a filosofia crítica. Para dar uma resposta, será útil considerar de novo o "construtivismo" nas posições de Fichte e Kant.

\section{As duas abordagens epistêmicas de Fichte e Kant}

32 Kant, que é extremamente sensível às complexidades de uma argumentação filosófica, muitas vezes tem dificuldades para se decidir. Nem sempre se admite que ele se inclina em direção a duas abordagens incompatíveis do conhecimento, que eu chamarei representacionismo e construtivismo. 

abordagem representacional do conhecimento. Por representacionismo eu tenho em mente a abordagem epistemológica mediante a relação de uma idéia na mente com uma coisa fora dela. Esta abordagem, que nasce com a filosofia grega, continua através da tradição moderna inteira, tanto antes como depois de Kant. O representacionismo é formulado muitas vezes como uma teoria causal da percepção. Uma teoria causal da percepção considera a idéia na mente como um efeito. O conhecimento supõe uma inferência retroativa do efeito para a sua causa, da ideia para a coisa ou o mundo.

Uma abordagem causal da percepção está presente de modo amplo na filosofia moderna. Uma abordagem causal como representacional, de modo análogo, perpassa a primeira Crítica, em que Kant entende a sensação como efeito causal dos noumena.

O representacionismo é bem conhecido, mas controverso. Uma abordagem causal da percepção exige uma inferência do efeito para a causa. Esta abordagem já é rejeitada por Platão, que nega qualquer inferência do efeito para a causa, p. ex., ao criticar as pretensões cognitivas da arte mimética. Kant, que reivindica ser platônico em sentido arraigado, concorda com Platão ao sugerir que objetos independentes da mente não podem ser conhecidos. Contudo, ele discorda de Platão, que acredita que alguns indivíduos podem ter uma intuição cognitiva do real ou noumena. Kant o rejeita, como rejeita a intuição intelectual. Portanto, ele afirma e nega o representacionismo, paradoxalmente. já foi compreendido em vida, por Maimon e depois Hegel, como um cético epistemológico. Embora negue o conhecimento dos noumena, ele afirma o conhecimento do empiricamente real. A sua segunda abordagem, incompatível, é construtivista. Por "construtivismo" tenho em mente a tese surpreendente, citada acima, que nós só conhecemos aquilo que, de certo modo, construímos. O construtivismo é formulado por Kant como uma solução substituta, depois da rejeição do representacionismo, ao problema do conhecimento. 0 construtivismo epistêmico é um fio central, afirmado de modos diferentes, a perpassar as visões de vários pensadores do período, incluindo tanto Fichte como Marx -que, sob este aspecto, é um idealista alemão.

37 Fichte é um construtivista epistêmico. Uma vez que ele não apenas se afirma kantiano, mas de fato é, e uma vez que o construtivismo de Kant muitas vezes não é reconhecido, não é surpreendente que o construtivismo de Fichte e, portanto, as dimensões da sua contribuição ao conhecimento, não sejam reconhecidos. Um recurso para entender o construtivismo de Fichte é a consideração da sua "Dedução da representação", que é central à Wissenschaftslehre de Jena. $O$ título desta seção sugere que Fichte deseja propor uma forma diferente e melhor do que a posição de Kant. Com certeza, a intenção é esta. Mas ele não o faz defendendo a representação. Na verdade, ele a rejeita.

A este respeito, Fichte propõe argumentos diferentes que levam ao mesmo resultado. Há três tópicos envolvidos. Um é que a ciência e a experiência são dois lados da mesma moeda. Esta é uma versão da tese de Kant sobre o aspecto duplo, ou a visão que fenômenos e númenos são dois aspectos da mesma coisa. Se isto fosse correto, então nós poderíamos de fato conhecer os númenos. Ainda assim, Kant não propõe um argumento e não há nenhum, em Kant, para mostrar que (usando a linguagem kantiana) aparência e realidade convirjam. Um segundo argumento é que o realismo, isto é, uma abordagem causal do conhecimento, não pode explicar o que só pode ser 
explicado pelo idealismo. Este argumento pressupõe uma distinção fundamental entre idealismo e realismo, ou materialismo, que Fichte propõe na Primeira Introdução à Doutrina da Ciência. Isto leva a uma rejeição clara de qualquer abordagem causal do conhecimento, portanto a uma rejeição do representacionismo em todas as suas formas. Na posição de Kant, isto leva à tese que não se pode reivindicar o impacto dos númenos sobre o sujeito, uma conclusão que Fichte tira ao rejeitar a própria concepção de coisa em si mesma.

Um terceiro argumento ainda é a tese que os problemas práticos só podem ser resolvidos no nível teórico mediante a atribuição ao sujeito da capacidade de postular (setzen) ou construir o mundo enquanto experimentado. Esta asserção é raramente compreendida. Fichte não está propondo uma doutrina contrafactual, notoriamente criticada por Heine, da criação do mundo a partir da sua própria cabeça. Ao contrário, ele está propondo uma forma de insight construtivista kantiano de que o que experimentamos, portanto que a experiência, em todas as suas formas, pode ser entendido mediante a atribuição de atividade epistêmica ao sujeito cognitivo.

\section{Conclusão: Fichte e o idealismo (alemão)}

40 Este artigo examinou a relação de Fichte e Kant contra o pano de fundo do idealismo alemão. Eu sugeri que o idealismo alemão surgiu com a revolução copernicana de Kant, cujo insight construtivista perpassa as visões de Kant e de seus sucessores idealistas alemães. Além disso, sugeri que o idealismo de Fichte é uma versão da visão kantiana do construtivismo, ou, dito de outro modo, a tese segundo a qual nós só conhecemos o que construímos.

41 Esta tese difícil é bastante criticada, mas raramente compreendida. Embora Fichte se afaste de Kant em pontos importantes, ele permanece, em um sentido específico, comprometido com uma abordagem construtivista do conhecimento.

42 A relação de Fichte com Kant é obscura, em parte, porque a filosofia crítica ainda não é bem compreendida. A Wissenschaftslehre difere, em muitos sentidos, da filosofia crítica. Ainda assim, na sua ênfase sobre o construtivismo, ela identifica e preserva o que eu acredito ser o insight mais profundo e mais interessante da filosofia crítica.

43 Kant intervém em um ponto crucial da tradição moderna. Mediante o representacionismo, ele continua com o "new way of ideas", enquanto o leva ao apogeu. Contudo, ao também rejeitar o representacionismo, ele caminha para o construtivismo, que é central ao idealismo alemão em todas as suas formas, e que permanece, mais de dois séculos depois, talvez a abordagem epistêmica mais interessante.

O construtivismo de Fichte, portanto sua relação com a revolução copernicana de Kant, não é muito discutido. Fichte reage à combinação híbrida kantiana de análise causal e sujeito ativo dispensando a primeira, e enfatizando o segundo. $O$ custo disso reside no enfraquecimento aparente da ênfase sobre a objetividade do conhecimento em Kant, que Schelling imediatamente se encarrega de remediar. Partindo de Fichte, Schelling restaura uma versão da visão kantiana ao enfatizar que a filosofia transcendental precisa ser acrescida de uma filosofia da natureza.

45 Fichte responde a Schelling, por exemplo, em suas Bemerkungen bei der Lektüre von Schellings transcendentalen Idealismus, escritas em 1800, imediatamente após o aparecimento do livro de Schelling e logo antes da ruptura de Schelling com Fichte. 
Com respeito à divisão que Schelling faz da filosofia em duas ciências básicas, a filosofia da natureza e a filosofia transcendental, Fichte escreve:

[..] aber jene Natur, also Objekt, denkst du doch nur: und sie ist nur, inwiefern Du sie denkst. Sie lässt im System des tr. Id [sc. transcendentalen Idealismus] dadurch nur, dass von der Intelligenz abstrahirt wird [...][sich] erklären. ${ }^{1}$

Portanto, se Fichte está correto, a única solução filosófica jaz, como ele sugere, em compreender a natureza, e literalmente tudo o mais, da perspectiva do sujeito.Eu concluirei com duas questões. Fichte, sem dúvida, constata e desenvolve um tema central em Kant ao desenvolver a abordagem construtivista do conhecimento. Embora Fichte reivindique ser fiel, a seu modo, à filosofia crítica, o resultado complexo é que ele é tanto fiel quanto infiel. Em outras palavras, ele é fiel a Kant do modo como os grandes filósofos são fiéis aos seus predecessores, isto é, ao lê-los a contrapelo das suas posições. Mas esta é outra história.

\section{NOTAS}

1. GA II/5, 413. "Mas esta natureza, portanto objeto, você apenas a pensa; e ela só é para você conforme você a pensa. Ela só pode ser explicada no sistema do idealismo transcendental que é abstraído da inteligência."

\section{RESUMOS}

The present paper explores the complex relation between Kant and Post-Kantian German Idealism and more specifically the relation between Kant and Fichte. What is German Idealism? What kind of 'idealism' is meant to be characteristic of the so-called German Idealists? How did Hegel and Fichte read Kant? To what extent was Fichte faithful to the Kantian philosophical motives? Is transcendental philosophy a representationalist or constructivist philosophy? In order to answer these questions I begin with an analysis of how Marxism and Analytical philosophy have understood 'idealism'. Then I examine the polysemy of the term 'idealism' in the history of western philosophy from Plato to $19^{\text {th }}$ Century British Idealism. The last four sections are dedicated to German Idealism's reception of Kantian philosophy and the development of my thesis about constructivism, transcendental philosophy and German Idealism. I will suggest that German idealism came up with the Copernican revolution of Kant, whose constructivist insight permeates the views of Kant and his German idealist successors. Furthermore, I will suggest that the idealism of Fichte is a version of Kantian constructivism, or, put another way, the argument that we only know what we have built. 
ÍNDICE

Keywords: analytical philosophy, constructivism, german idealism, representationalism

AUTOR

TOM ROCKMORE

Duquesne University/University of Peking 